\title{
A new method for measuring optical scattering properties of atmospherically relevant dusts using the Cloud and Aerosol Spectrometer with Polarization (CASPOL)
}

\author{
A. Glen and S. D. Brooks \\ Department of Atmospheric Sciences, MS 3150, Texas A\&M University, College Station, Texas, 77843-3150, USA
}

Correspondence to: S. D. Brooks (sbrooks@tamu.edu)

Received: 31 July 2012 - Published in Atmos. Chem. Phys. Discuss.: 30 August 2012

Revised: 5 January 2013 - Accepted: 7 January 2013 - Published: 1 February 2013

\begin{abstract}
Atmospheric aerosols have major impacts on regional and global climate through scattering and absorption of solar radiation. A new instrument, the Cloud and Aerosol Spectrometer with Polarization (CASPOL) from Droplet Measurement Technologies measures light scattered by aerosols in the forward $\left(4^{\circ}\right.$ to $\left.12^{\circ}\right)$ and backward $\left(168^{\circ}\right.$ to $176^{\circ}$ ) directions, with an additional polarized detector in the backward direction. Scattering by a single particle can be measured by all three detectors for aerosols in a broad range of sizes, $0.6 \mu \mathrm{m}<$ diameter $<50 \mu \mathrm{m}$. The CASPOL is a unique measurement tool, since unlike most in-situ probes, it can measure optical properties on a particle-by-particle basis. In this study, single particle CASPOL measurements for thirteen atmospherically relevant dusts were obtained and their optical scattering signatures were evaluated. In addition, Scanning Electron Microscopy (SEM) was used to characterize the shape and morphology of each type of dust. The total and polarized backscatter intensities varied with particle size for all dust types. Using a new optical signature technique all but one dust type could be categorized into one of three optical scattering groups. Additionally, a composite method was used to derive the optical signature of Arizona Test Dust (ATD) by combining the signatures of its major components. The derived signature was consistent with the measured signature of ATD. Finally, calculated backscattering cross sections for representative dust from each of the three main groups were found to vary by as much as a factor of 7 , the difference between the backscattering cross sections of white quartz $\left(5.3 \times 10^{-10} \mathrm{~cm}^{-2}\right)$ and hematite $\left(4.1 \times 10^{-9} \mathrm{~cm}^{-2}\right)$.
\end{abstract}

\section{Introduction}

Mineral dusts strongly influence the Earth's radiative budget through scattering and absorption of light (Attwood and Greenslade, 2011; Sassen, 2002). Atmospheric dust comprises approximately $45 \%$ of the total aerosol mass loading of the atmosphere (Caquineau et al., 2002). The direct radiative impact of this loading produces an estimated net cooling effect of approximately $-0.1 \mathrm{Wm}^{-2}$ (IPCC, 2007). In addition, atmospheric dust influences liquid droplet and ice nucleation (Chen et al., 1998; Kanji and Abbatt, 2009), the deposition of micronutrients into oceans (Duce and Tindale, 1991; Uematsu et al., 2003) and regional air quality (Prospero, 2006; Prospero et al., 2001). Mineral dust lifetimes in the troposphere can be on the order of a week for particles smaller than $10 \mu \mathrm{m}$, while larger particles are removed faster by sedimentation due to gravity and by precipitation (Attwood and Greenslade, 2011). Hence, deposition occurs hundreds and sometimes thousands of miles from the source. For example, Saharan dust can spread along three major pathways: westward over the Atlantic Ocean to the Americas, northward over the Mediterranean to Europe, and eastward to the Middle East (Goudie and Middleton, 2001). Several other source regions around the world are characterized by dusts of differing physical and chemical properties and areas of influence. For example, the Simpson-Stzelecki Desert of Central Australia is rich in iron oxides (Bullard and White, 2002), while the Gobi Desert is composed primarily of crustal material and carbonates (Xu et al., 2004). Various dusts have visibly observable differences, such as color which is often a sign of oxidation state and surface morphology which is an indication of atmospheric aging and 
processing (Bullard and White, 2002). Aerosol optical properties are influenced by the composition, age, shape, morphology, refractive index, number concentration and size distribution of the particle population.

The direct radiative effect of light scattering by spherical aerosols can be calculated using Mie theory (Bohren and Huffman, 2004; Morgan et al., 2010). However, the optical properties of non-spherical particles such as dust are more challenging to predict theoretically. One approach is to calculate the volume equivalent spherical size and use that in Mie calculations. This method leads to significant differences between non-spherical particles and spherical particles of equivalent size (Mishchenko et al., 1997; West et al., 1997). Other methods such as T-Matrix (Mishchenko et al., 1997), Discrete Dipole Approximation (DDA) and Improved Geometric Optics Methods (IGOM) for modeling optical properties of particles with specified geometries can be used (Bi et al., 2009). However, experimental validation is needed to examine the applicability of these numerical methods for determining the optical properties of non-spherical particles.

While many laboratory studies have investigated the optical properties of non-spherical dusts, properties are typically determined for ensembles of particles (Arakawa et al., 1997; Attwood and Greenslade, 2011; Curtis et al., 2008; West et al., 1997). For example, Attwood and Greenslade (2011) determined the relative humidity dependence of light extinction for three clays, including illite, kaolinite, and montmorillonite. Curtis et al. (2008) measured the scattering of light by populations of dusts over a larger range of collection angles, approximately $17^{\circ}$ to $176^{\circ}$. The dust samples used in that study were Arizona Test Dust (ATD), silicate clays including illite, kaolinite, and montmorillonite, and non-clay minerals such as calcite, gypsum, hematite, and quartz. The scattering phase function of non-spherical mineral dusts over multiple scattering angles $\left(15^{\circ}\right.$ to $\left.170^{\circ}\right)$ was measured by West et al. (1997). Their results showed variation in the change in polarization state of light depending on the types of dust sampled.

Remote sensing measurements of ambient atmospheric dust are important, as they provide a much greater spatial and temporal coverage of dust ensembles than in-situ measurements. In addition, the use of multiple detectors and wavelengths provides additional information on particle properties. For example, depolarization ratio, defined as the ratio of returned powers in the planes of the polarization orthogonal and parallel to that of the linearly polarized source, can be used to determine particle sphericity (Sassen, 1991). Mishchenko et al. (1997) showed that even after applying particle size and orientation averaging, a single spheroidal shaped particle always produces a unique shape specific phase function distinctly different from those produced by other spheroidal particles. Thus depolarization ratios can be used to differentiate non-spherical or rough particles from spheres. For example, a dual wavelength Mie scattering lidar was employed to obtain aerosol particle size information and sphericity for Asian dust and anthropogenic plumes in the Northwest Pacific (Sugimoto et al., 2002). The depolarization ratio is also dependent on the orientation of the nonspherical particles, i.e. horizontally orientated particles have different backscatter and depolarization characteristics than vertically orientated particles (Cho et al., 2008). Highly irregular particle morphologies typically have a low backscatter signal and a high depolarization ratio (Cho et al., 2008). Although depolarization ratio is the working definition for a parameter used in numerous studies, it has been noted that technically the interaction between particles and linearly polarized light does not explicitly depolarize the incident light but instead changes the state of the polarized light (HarrisHobbs and Cooper, 1987).

This study focuses on the development of a prototype instrument to measure the single particle scattering properties of atmospherically relevant dusts, specifically the forward scattering intensity, total backscatter intensity and polarized backscatter intensity. The prototype Cloud and Aerosol Spectrometer with Polarization (CASPOL) recently developed by Droplet Measurement Technologies (DMT) is an optical particle counter based on the forward and backward scattering capability of the Cloud and Aerosol Spectrometer (CAS) sensor of the Cloud Aerosol and Precipitation Spectrometer (CAPS) (Baumgardner et al., 2001, 2011). However, this new instrument has two key features which set it apart from the CAS. First, in addition to forward and backward scattering intensity, the polarized backscattering intensity is also measured. Second, data is collected on a single particle basis which provides a measure of particle-by-particle variability and single particle optical properties.

\section{Cloud and Aerosol Spectrometer with Polarization (CASPOL)}

The first objective of this study was to test the ability of the newly designed CASPOL instrument to detect forward, total and polarized backscattered light from spherical particles, and various types of non-spherical dusts generated in the laboratory. The second objective was to determine the feasibility of using the CASPOL to differentiate between the optical properties of various types of non-spherical dusts. Single particle CASPOL measurements for a collection of atmospherically relevant dusts were obtained. The optical signatures of the dusts were evaluated to test whether dusts from certain source locations had unique signatures which could be used to determine dust type sampled during in-situ measurements. In addition, differences in optical scattering provide insight into potential differences in aerosol direct effects on climate.

The CASPOL employs a linearly polarized laser to provide a collimated incident beam of light at a wavelength of $680 \mathrm{~nm}$ (Fig. 1). There are four detectors in the instrument, with collection angles of $4^{\circ}$ to $12^{\circ}$ for the forward detectors and $168^{\circ}$ to $176^{\circ}$ for the backward detectors, as 


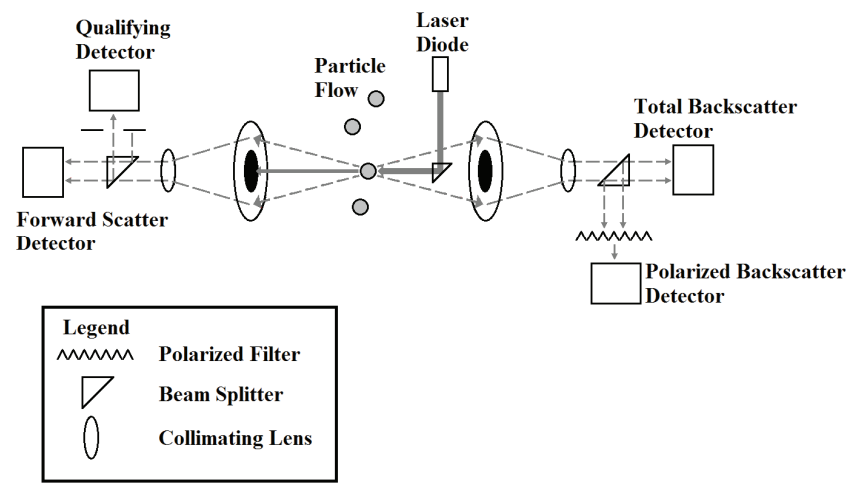

Fig. 1. Schematic of the CASPOL instrument (DMT Manual, 2011).

seen in Fig. 1. The particle's water equivalent optical diameter is determined from the primary forward scattering signal. Note that in this manuscript, diameter refers to the water equivalent optical diameter, not the geometric diameter. The CASPOL can measure light scattering from particles over a size range of $0.6 \mu \mathrm{m}$ to $50.0 \mu \mathrm{m}$ in diameter. Light scattered in the backward direction passes through a beam splitter which directs light to two independent detectors. One of the backward detectors measures the total backscatter intensity. The intensity of scattered light in the backward direction gives insight into particle shape, as it is more dependent on shape than scattering in the forward direction is. The second backward detector measures perpendicularly polarized backscatter intensity over the same angles as the total backward detector. The polarized backscatter detector is used in conjunction with the total backscatter detector to calculate the polarization ratio. The polarization ratio, $\delta$, used in this paper is defined in Eq. (1) below.

$\delta_{168^{\circ}}^{176^{\circ}}=\frac{\text { Polarized Backscatter Intensity }}{\text { Total Backscatter Intensity }}$

Since the collection angles of light in the backward direction are not quite at $180^{\circ}$ and the prototype CASPOL instrument used here employs a total backscattering detector rather than a parallel polarized light detector, the resulting polarization ratio differs from the depolarization ratio used by the lidar community. Similar to the lidar depolarization ratio, the theoretical polarization ratio for a spherical liquid droplet is approximately zero. Finally, there is an additional detector in the forward direction which is used as a qualifier. The qualifier detector has an optical mask which restricts scattered light from particles that are further than $0.75 \mathrm{~mm}$ from the center of focus of the laser beam (DMT Manual, 2011). Particles which are within the depth of field $( \pm 0.55 \mathrm{~mm}$ either side of the center of focus) are measured using the qualifier detector. The beam splitter which separates the two detectors is split with $70 \%$ of the light delivered to the qualifier and $30 \%$ delivered to the forward scattering detector. Each time the qualifier detector signal exceeds the forward scatter-

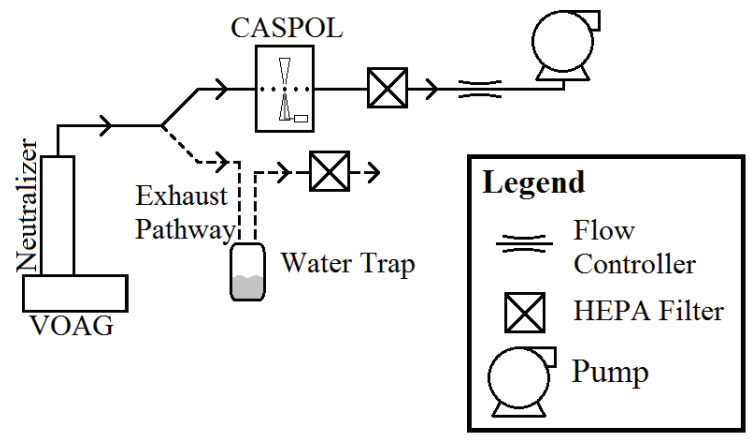

Fig. 2. Experimental setup used to calibrate the CASPOL using a TSI Vibrating Orifice Aerosol Generator (VOAG).

ing detector signal, the peak amplitude of the scattered light signal is recorded and counted as a particle.

\subsection{CASPOL size calibration}

To calibrate the CASPOL particle sizing, a TSI 3450 Vibrating Orifice Aerosol Generator (VOAG) with a $20 \mu \mathrm{m}$ diameter orifice was used (Fig. 2). A series of calibration experiments were performed on particles ranging from $2 \mu \mathrm{m}$ to $19 \mu \mathrm{m}$ diameter. The VOAG generates a monodisperse distribution of spherical particles by forcing a suspension of olive oil and isopropyl alcohol through a small orifice powered by a motorized syringe. During operation, an AC signal generator is used to induce oscillation in a piezoelectric ceramic disk. The oscillation is transmitted directly to the orifice causing breakup of the otherwise cylindrical jet of solution. The mean particle diameter generated by the VOAG depends on the initial concentration of the solution, the frequency of oscillation, the syringe feed rate, and the orifice diameter (Liu et al., 1974). The theoretical VOAG diameter, $D_{\mathrm{p}}$ is calculated by Eq. (2) (TSI Manual, 2002):

$D_{\mathrm{p}}=C^{\frac{1}{2}}\left(\frac{6 Q}{\pi f}\right)^{\frac{1}{3}}$

where $C$ is the volumetric concentration of solute in the solution, $Q$ is the syringe flow rate of the solution and $f$ is the frequency of oscillation.

Individual droplets escaping the orifice are transported through the VOAG neutralizer and chamber by a dispersion flow of filtered air which also acts to evaporate the isopropanol, leaving pure olive oil droplets, with a refractive index of 1.46 (Yunus et al., 2009). Next the flow of particleladen air is distributed between two pathways. The first pathway leads to the CASPOL at a flow rate of $1.2 \mathrm{~L} \mathrm{~min}^{-1}$ controlled by a mass flow controller (Alicat Scientific Inc, MCP20SLPM) and pump. The second pathway is an exhaust to reduce the air flow rate and pressure of the system. Nearmonodisperse distributions of particles were generated by the VOAG and sampled by the CASPOL over the broad size range, 0.6 to $50 \mu \mathrm{m}$. 
Table 1. Properties of the dust type included in this study.

\begin{tabular}{|c|c|c|c|c|c|c|c|c|c|}
\hline & \multicolumn{2}{|c|}{ Refractive Index } & \multirow[b]{2}{*}{ Source** } & \multirow{2}{*}{$\begin{array}{l}\text { Primary Mode } \\
\text { Diameter }(\mu \mathrm{m})\end{array}$} & \multirow{2}{*}{$\begin{array}{l}\text { Secondary Mode } \\
\text { Diameter }(\mu \mathrm{m})\end{array}$} & \multicolumn{2}{|c|}{ Aspect Ratio } & \multirow[b]{2}{*}{ Group } & \multirow[b]{2}{*}{ Reference } \\
\hline & Real & Complex & & & & Mean & St. Dev & & \\
\hline Arizona Test Dust & 1.51 & $1.02 \times 10^{-3}$ & $33.38^{\circ} \mathrm{N},-112.31^{\circ} \mathrm{E}$ & 2.0 & 0.61 & 1.5 & 0.3 & - & Powder Technology Inc \\
\hline Hematite & 2.31 & & Sigma Aldrich & 2.0 & 0.61 & 2.4 & 1.4 & A & Kerker et al. (1979) \\
\hline Kaolinite & 1.57 & $6.60 \times 10^{-3}$ & Sigma Aldrich & 2.0 & 5.0 & 1.5 & 0.4 & A & Arakawa et al. (1997) \\
\hline Gypsum & 1.61 & $0.01 \times 10^{-3}$ & Sigma Aldrich & 0.61 & 1.5 & 2.3 & 0.4 & $\mathrm{~B}$ & Ivlev and Popova (1973) \\
\hline Quartz & 1.54 & $0.01 \times 10^{-3}$ & Fluka & 0.61 & 1.5 & 1.9 & 0.7 & B & Filmetrics Database \\
\hline Red New Mexico & $*$ & & $35.82^{\circ} \mathrm{N},-106.62^{\circ} \mathrm{E}$ & 0.61 & 1.5 & 1.5 & 0.5 & B & \\
\hline Red Saudi Arabia & $*$ & & $24.37^{\circ} \mathrm{N}, 46.25^{\circ} \mathrm{E}$ & 0.61 & 1.5 & 2.0 & 0.5 & $\mathrm{~B}$ & \\
\hline White Quartz & 1.54 & $0.01 \times 10^{-3}$ & Sigma Aldrich & 0.61 & 1.5 & 1.7 & 0.2 & $\mathrm{~B}$ & refractiveindex.info Database \\
\hline White Sands & $*$ & & $32.88^{\circ} \mathrm{N},-106.35^{\circ} \mathrm{E}$ & 0.61 & 1.5 & 1.9 & 0.7 & $\mathrm{~B}$ & \\
\hline Magnetite & 2.15 & & Aldrich Chemicals & 1.5 & 0.61 & 1.8 & 0.7 & $\mathrm{C}$ & Schlegel et al. (1979) \\
\hline Montmorillonite & 1.53 & $1.47 \times 10^{-3}$ & Sigma Aldrich & 0.61 & 1.5 & 1.6 & 0.3 & $\mathrm{C}$ & Arakawa et al. (1997) \\
\hline Yellow Saudi Arabia & $*$ & & $25.27^{\circ} \mathrm{N}, 46.67^{\circ} \mathrm{E}$ & 1.5 & 0.61 & 1.5 & 0.2 & $\mathrm{C}$ & \\
\hline Zeolite & 1.49 & & Sigma Aldrich & 0.61 & 1.5 & 1.2 & 0.1 & $\mathrm{C}$ & Li et al. (2010) \\
\hline
\end{tabular}

* Indicates field collected sample with no measurement of refractive index.

** The source of the sample is included for commercially available dusts, for field samples the source is listed as the location of collection.

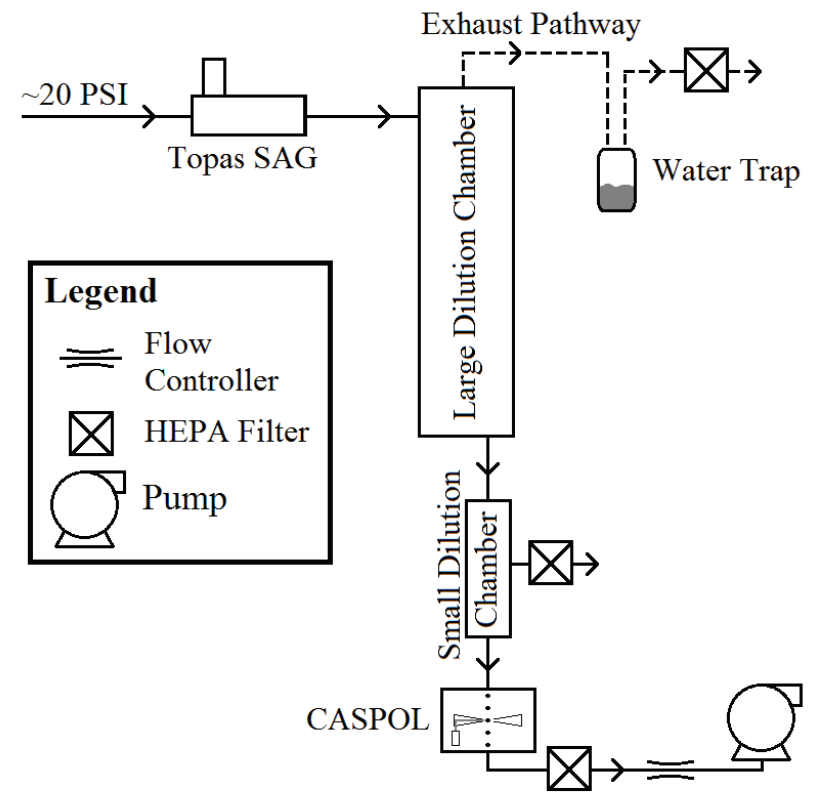

Fig. 3. Experimental setup for CASPOL dust measurements.

\subsection{Measurements of the optical scattering signatures of atmospheric dust particles}

To measure the scattering properties of the dust samples, experiments were conducted using the setup shown in Fig. 3. These experiments used a Topas Solid Aerosol Generator 410 (SAG) to generate a polydisperse distribution of dust. The SAG allows the dust to be aerosolized without the need of a suspension liquid such as water, ensuring the aerosol particles are completely dry. Within the SAG, a rotating scraper evenly fills sample spaces in a toothed conveyor belt. The belt then transports the individual amounts of sample to an ejector nozzle which aerosolizes the sample by means of a high pressure dry nitrogen inlet.
All of the dusts were generated using the same control settings for the input pressure of $20 \mathrm{psi}$, a preparation rate set at 3 (dictating how fast the dust scraper rotates and deposits dust on the belt) and a belt speed set at $0.3 \%$ of maximum speed. Thus, any observed differences in aerosol size distributions reflect the intrinsic differences in dust samples rather than operating conditions. The aerosolized dusts were directed to a large dilution chamber, which allowed for a reduction in particle concentration and total flow of the aerosol stream by removing air via the exhaust pathway. At the output of the large dilution chamber is a smaller dilution chamber with two outlets, one for sampling and one for a filtered exhaust outlet allowing the system to be kept at near ambient atmospheric pressure (Fig. 3). Next, the CASPOL drew aerosol-laden air from the sample line at a flow rate of $1.2 \mathrm{~L} \mathrm{~min}^{-1}$, identical to the calibration flow rate. CASPOL data was recorded for each single particle. The CASPOL's single particle temporal resolution is $5 \mathrm{~ms}$. The sampling time varied from $\sim 30$ to $100 \mathrm{~min}$, to ensure that at least $\sim 10^{5}$ particles were sampled per experiment. Additionally, during the experiments, samples of each dust were diverted from the CASPOL aerosol stream and directed to a single stage PIXE impactor for subsequent imaging using Scanning Electron Microscopy (SEM), as discussed further in Sect. 2.3.

The thirteen dust types included in these experiments and their sources are listed in Table 1. Eight of these were commercially available single component samples. The last commercially available sample, Arizona test dust, is a well characterized multi-component specimen primarily composed of three components, montmorillonite, kaolinite and hematite in weight percentages of $\sim 45,45$, and $10 \%$, respectively, as described by the manufacturer (Powder Technology Inc.). In addition, four dust field samples collected from ground sites around the world, including two from different locations in Saudi Arabia and two from different locations in 


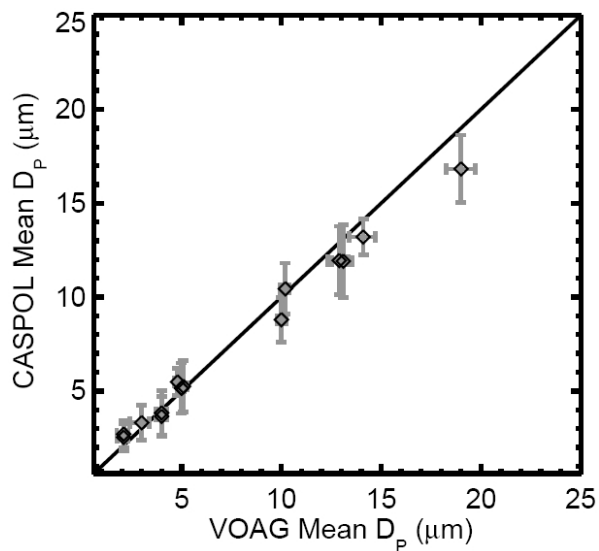

Fig. 4. Size calibration of the CASPOL. The theoretical VOAG mean particle diameter is on the abscissa and the measured CASPOL mean diameter is on the ordinate. The error bars represent measurement uncertainties in both determinations of diameters.

New Mexico, USA were used. The latitude and longitude of each field sampling location is included in Table 1. Values of the refractive indices of the commercial dusts reported in the literature are also listed in the table. Reported values for the real component of refractive index range from 1.49 for zeolite to 2.31 for hematite (Kerker et al., 1979; Li et al., 2010). The imaginary part of the refractive index is small for most of these dusts (Curtis et al., 2008), with the exception of hematite and magnetite which are strong absorbers of visible light.

\subsection{Scanning Electron Microscopy (SEM)}

Scanning Electron Microscopy (SEM) was used to observe particle morphology using a JEOL 6400 microscope. During approximately $30 \mathrm{~min}$ of each CASPOL experiment, a sample was collected on an aluminum foil disk mounted on a PIXE $0.5 \mu \mathrm{m}$ impactor stage. Particles were subsequently taken to the Microscopy and Imaging Center on the Texas A\&M University Campus for SEM analysis. In preparation for SEM analysis which requires electrical conductivity, samples were vapor stabilized using osmium tetroxide and then sputter coated with gold and platinum (Ellis and Pendleton, 2007). SEM images were taken at a resolution of $3.5 \mathrm{~nm}$ for all dust types and these images were used to identify differences and similarities in particle shape.

\section{Results}

\subsection{CASPOL size calibration results}

Results of the CASPOL size calibration are shown in Fig. 4. In general, diameters measured by the CASPOL for olive oil particles are in good agreement with those chosen by the VOAG operating conditions. The uncertainties shown in

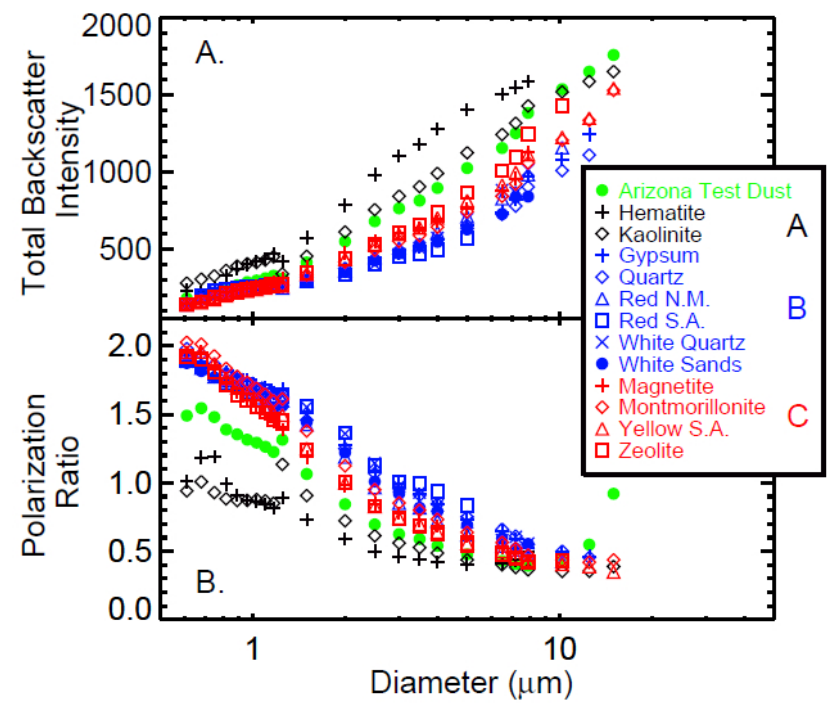

Fig. 5. Total backscatter intensity and polarization ratio as a function of particle diameter for all dust types. Individual dust types identified as members of optical scattering Groups A, B, and C are represented by black, blue, and red symbols, respectively. Data for Arizona Test Dust, the one outlier in the study, is represented by green circles.

Fig. 4 for the VOAG diameters are based on the uncertainty in the theoretical calculation of the VOAG generated particle diameters, as described in the instrument manual (TSI Manual, 2002). The uncertainties in the CASPOL diameters are the standard deviations from the mean diameter of the log normal size distributions fitted to the CASPOL measured calibration particle size generated by the VOAG. At diameters less than $10 \mu \mathrm{m}$, the agreement between the VOAG and CASPOL is within $25 \%$. At particle diameters larger than $13 \mu \mathrm{m}$ there is some deviation between the CASPOL and the VOAG. This may be due to a combination of factors. At relatively large particle sizes, the VOAG has been known to misssize particles, with actual particle size not being accurately predicted by theory (Peters et al., 2008). This may be due to the increase in the surface stress of the droplet at larger volumes which causes a deformation of a particle from spherical to non-spherical and subsequently induces breakup. Also, the manufacturer's size calibration of the CASPOL is based on water equivalent particles. Due to the differences in refractive indices between water and olive oil, diameters of oil droplets determined in our calibration will be overestimated by as much as $\sim 30 \%$. For example a $1.9 \mu$ m oil particle has a water equivalent diameter of $2.5 \mu \mathrm{m}$.

\subsection{Optical scattering of atmospheric dust particles}

The average total backscatter intensity and polarization ratio of all the particles per size channel, are shown in Fig. 5a and $b$, respectively. In general, the total backscattering intensity increased with size for all of the dust types. However, 
variations in total backscatter intensity of up to a factor 3 were observed depending on particle composition. At most diameters, red Saudi Arabian dust had the lowest total backscatter intensity and the hematite had the highest. The observed variation in total backscatter intensity proved to be helpful in categorizing aerosol types as discussed further below.

Figure $5 \mathrm{~b}$ shows that particles in the submicron sizes have the largest values of polarization ratio. For submicron particles, the polarization ratio ranged from $\sim 1.0$ for kaolinite to $\sim 2.0$ for montmorillonite. The polarization ratio in the figure shows a reduction with increasing particle diameter, suggesting that larger particles may be more spherical. Also, as the particle diameters increase, the variation between the polarization ratios of various dusts is reduced. It should be noted that polarization ratio values greater than unity were observed; this is a result of an instrumental artifact in this prototype unit and will be addressed in revised versions of the instrument by DMT.

Based on these raw data, the thirteen dust samples were sorted into three groups, with only one outlier. Groups A through $\mathrm{C}$ aptly describe the characteristics of all dust types except Arizona test dust, which is further discussed below. In Fig. 5 the group identifications for each individual dust type are denoted by the color of the symbols in the legend. We note that the standard deviation in measurements of both the total backscatter intensity and polarization ratio show significant overlap between dust types (not shown). To illustrate the range of total backscatter intensity values obtained for a single particle size, the distribution of total backscatter intensity as a function of dust type for one size channel of the CASPOL (2.5 to $3.0 \mu \mathrm{m}$ ) is shown in Fig. 6. The 2.5 to $3.0 \mu \mathrm{m}$ size channel was chosen as a good representative diameter since dust in this size range is transported globally (Prospero et al., 1970). In Fig. 6, the abscissa denotes the type of dust and the ordinate shows the relative total backscatter intensity, displayed in arbitrary units (a.u.). The legend indicates the percentage of the total number of particles in the 2.5 to $3.0 \mu \mathrm{m}$ size channel for that particular dust type which have the given total backscatter intensity.

The deviation in total backscatter intensity amongst particles within a single diameter bin is an indication of the degree of variation in the characteristics, specifically shape and surface roughness, of the individual particles within a single composition and size. Variation in the total backscatter intensity may also arise from differences in the particle orientation when passing through the CASPOL sampling region. As Fig. 6 shows, differences were observed in both the mean total backscatter intensity and the spread in intensity for various dust types. For particles in the 2.5 to $3.0 \mu \mathrm{m}$ size channel, the mean total backscattering intensity varied by more than a factor of 3 from a low of 280 a.u. for white sands to a high of 900 a.u. for hematite. The plots in Fig. 6 provide a more robust differentiation between groups A, B, and C. Members of Group A, hematite and kaolinite have
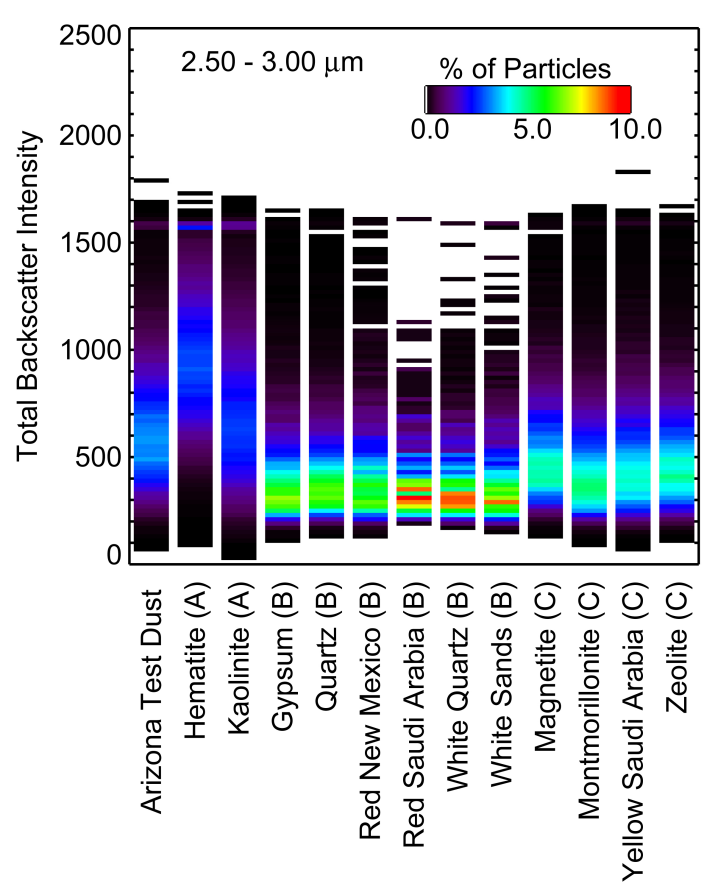

Fig. 6. For the 2.5 to $3.0 \mu \mathrm{m}$ CASPOL channel, the percentages of particles which have a given total backscatter intensity are shown for each dust type.

the majority of particles at total backscatter intensities above 500 a.u., with very large variability in total backscatter intensity, and no discernible peak intensity. Based only on these backscatter plots, Arizona test dust data was not discernible from members of Group A. Group B data is characterized by high peak frequencies (above $7 \%$ of the total), and peak total backscatter intensities less than 400 a.u. This group also has the lowest standard deviation in total backscatter intensity for a single size. Data from members of Group $\mathrm{C}$ features peak total backscatter intensities of less than 500 a.u., with peak frequencies less than $5 \%$ of the total particles in the 2.5 to $3.0 \mu \mathrm{m}$ channel.

Overall, these results indicate that particle size is influential but not the dominant factor in the total backscattering intensity. Other particle properties such as composition, refractive index, morphology, and orientation may also play a significant role in determining the intensity of backscattered light from a particle of given size. To further develop a systematic characterization of the dust samples into the listed groups, a new analysis was developed and is discussed in Sect. 3.5.

\subsection{Size distributions of characteristic dusts}

Size distributions based on CASPOL forward scattering measurements of at least $10^{5}$ particles were obtained for each dust type. The average size distributions measured by the CASPOL are shown in Fig. 7 for hematite (panel a), white quartz (panel b) and zeolite (panel c). As seen in Fig. 7, the 

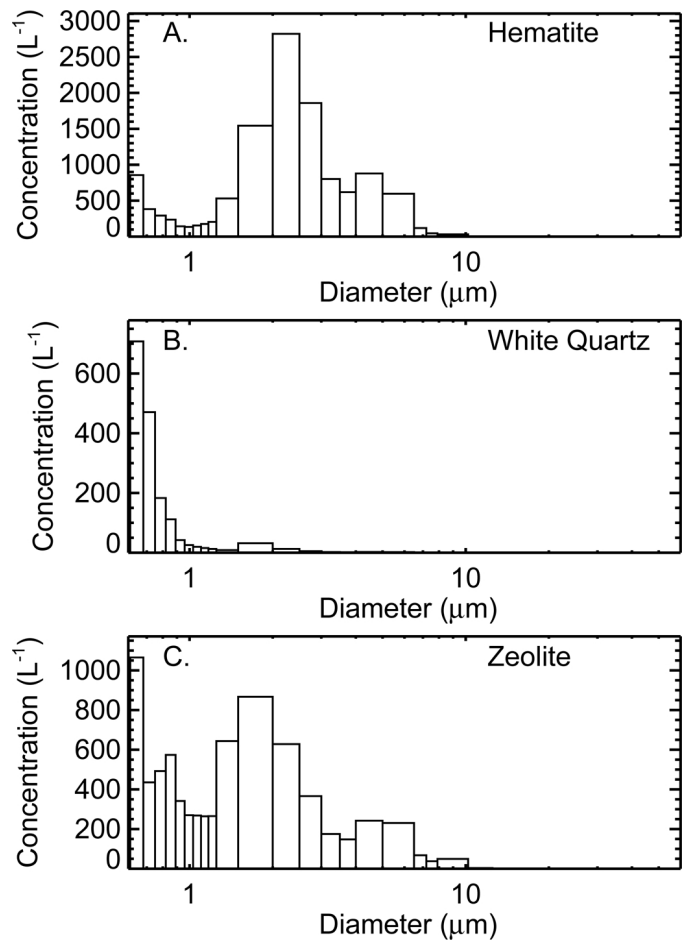

Fig. 7. Average particle size distributions as measured by the CASPOL for three dust types: hematite, white quartz and zeolite.

shape of the size distributions varied depending on the composition of the sample. All of the thirteen dust types produced size distributions with multiple modes. The primary and secondary mode diameter for all of the dust distributions are shown in Table 1. Eight of the thirteen samples generated by the SAG produced size distributions with a primary mode in the $0.6 \mu \mathrm{m}$ channel and a strong secondary mode at $1.5 \mu \mathrm{m}$. The remaining five dust types have a dominant mode at either $1.5 \mu \mathrm{m}$ or $2.0 \mu \mathrm{m}$, with a smaller mode at $0.6 \mu \mathrm{m}$. Four of the dusts, Arizona test dust, montmorillonite, yellow Saudi Arabia and zeolite display a third mode in the CASPOL measured size distributions between 4.5 and $5.0 \mu \mathrm{m}$. The two dusts in Group A, hematite and kaolinite have different size distributions, as hematite has a primary mode at $2.0 \mu \mathrm{m}$ and a secondary much lower concentration mode at submicron sizes. Kaolinite has a primary mode at $2.0 \mu \mathrm{m}$ and a secondary mode with a similar concentration to the primary at $5.0 \mu \mathrm{m}$. Group B were more consistent with the same mode diameters of the bimodal distribution for all dusts. Gypsum, red New Mexico, red Saudi Arabia, white quartz and white sands all have lower average concentrations with most size bins having concentrations below $300 \mathrm{~L}^{-1}$. However, the standard quartz sample has concentrations of nearly double those measured for the other five dusts in this group. Dusts in Group C all had very similar size distributions which have mode diameters at $0.6 \mu \mathrm{m}$ and $1.5 \mu \mathrm{m}$. In summary, Groups B and C have defining size distribution characteristics but Group A does not.

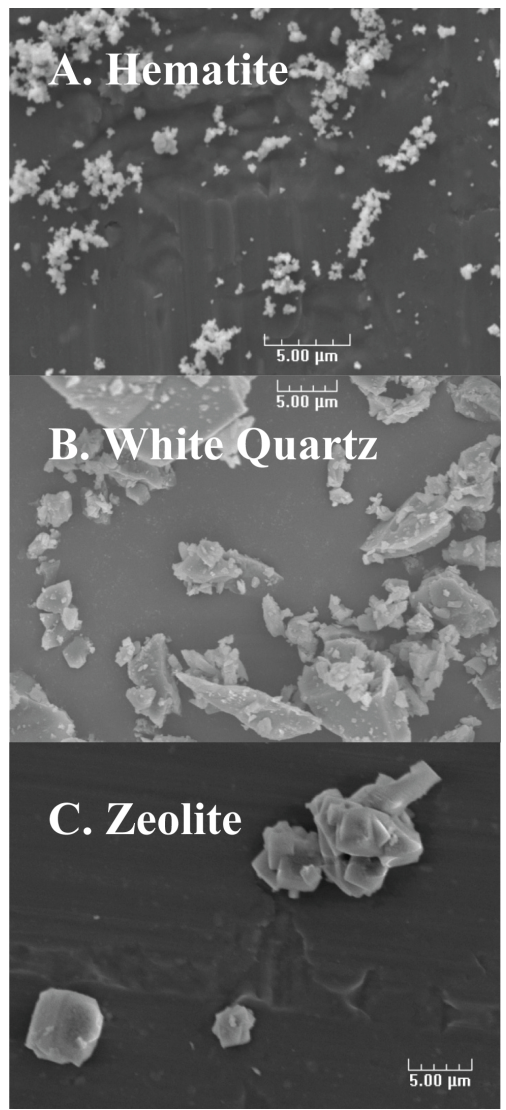

Fig. 8. SEM images of hematite, quartz, and zeolite particles are shown in (A), (B), and (C), respectively.

\subsection{Particle shape using scanning electron microscopy}

High resolution SEM images for the three representative aerosols are shown in Fig. 8. In each case, particle size ranges from submicron to supermicron in diameter. Hematite samples have long aggregates of supermicron size particles comprised of smaller more spherical submicron particles. Similarly, kaolinite is composed of smaller elongated spheroids clumped together to form larger supermicron particles. Gypsum particles are present as supermicron particles consisting of submicron blocks with round edges. The zeolite particles are very cubic and have individual particles clumped together to form agglomerates. Both quartz and white quartz samples are more irregularly shaped. Magnetite shows long chain aggregates and clumps of elongated spheroids. The montmorillonite sample has irregularly shaped spheroids. The average and standard deviation in aspect ratios for each dust were estimated using ImageJ software to analyze the SEM images (Table 1). The images do not yield any distinctive similarities for dust types allocated to the same groupings, indicating that shape and size are not the only determining factors in the optical scattering properties. 

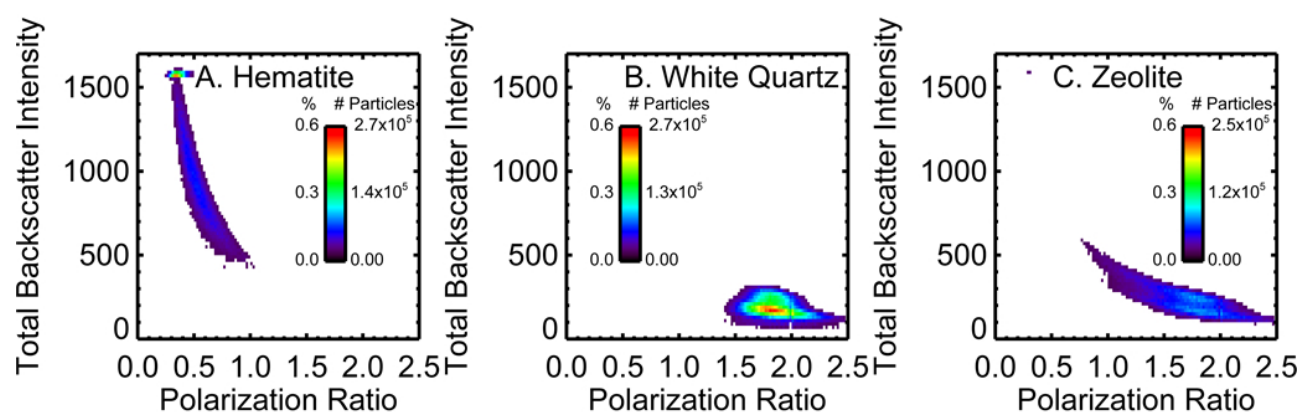

Fig. 9. Total backscatter intensity vs. polarization ratio for representative members of the optical scattering Groups A (hematite), B (white quartz) and C (zeolite) are shown.
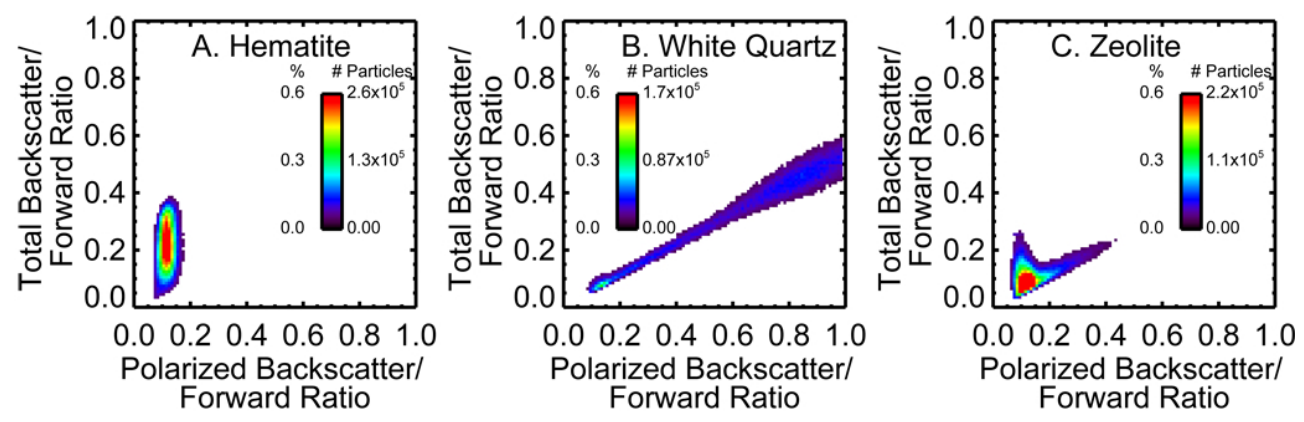

Fig. 10. Polarized backscatter to forward scatter ratio vs. total backscatter to forward scatter ratio for representative members of the optical scattering Groups A (hematite), B (white quartz) and C (zeolite) are shown.

\subsection{Categorization of dust types from optical signatures}

A new strategy using the optical properties of each dust type to categorize the dust groupings was developed. The range of each variable, forward scattering, total backscatter and polarization ratio, was discretized and the frequency of particles which had intersecting values was placed in each discretized bin. This analysis was completed for all the dust samples. For example, Fig. 9 shows the signature of total backscatter intensity vs. polarization ratio for the representative dusts. Similarly, the total backscatter to forward scatter ratio vs. the polarized backscatter to forward scatter ratio is shown in Fig. 10. Both sets of optical signature figures are for the same three dusts (Hematite, white quartz and zeolite), chosen to be representative of Groups A, B and C and shown in the figure panels $\mathrm{a}, \mathrm{b}$ and $\mathrm{c}$, respectively. Inspection of these signatures can provide a means to classify each sample into the optical category A, B, or C with certainty and without the aid of any auxiliary information. Signature details for each dust type are summarized in Table 2.

The signature shape of data in the total backscatter intensity vs. polarization ratio plots, and the number of particles in a certain spatial region in the pixel map are very important in differentiating between the three groups. The signature curve shape for Group A is a relatively steep curve in which all members have polarization ratios $<1$.0. In contrast, the Group B data can be described as a linear increase in po- larization ratio with approximately constant total backscatter intensity. All particles in Group B had polarization ratios of $>1.0$. Finally, Group $\mathrm{C}$ has a shallow curve of decreasing total backscatter intensity with increasing polarization ratio, and values of polarization ratio between $0.75-2.5$.

For the second signature type, the total backscatter to forward scatter ratio vs. the polarized backscatter to forward scatter ratio, the overall signature shape and the values of the polarized backscatter to forward scatter ratio are the dominant factors in determining the signature (Fig. 10). Members of Group A have a clustered distribution with polarized backscatter to forward ratio $<0.2$. The ensemble of dust particles in Group B show a linear monotonic increase in total backscatter to forward ratio with increasing polarized backscatter to forward ratio. Members of Group C, display a "V" shaped distribution with a maximum intensity $>1 \%$ of the total number of particles measured and polarized backscatter to forward ratio $<0.4$.

This method of identifying signatures based on the ratios of measured signals is powerful as it yields observable differences between dust types. With the exception of Arizona test dust, all of the dust samples collected in the field fit into one of the three groups using the signature method. Interestingly, dust samples from the two locations in Saudi Arabia were allocated to different groups despite their close geographical proximity, approximately $110 \mathrm{~km}$. To explore the 
Table 2. Rules for differentiating between dust Groups A, B, and C.

\begin{tabular}{|c|c|c|c|}
\hline \multicolumn{4}{|c|}{ Total Backscatter Intensity vs. Polarization Ratio } \\
\hline & Group A & Group B & Group C \\
\hline Shape & Steep Curve & Linear Decrease & Shallow Curve \\
\hline Polarization Ratio & $<1.0$ & $>1.0$ & $0.75<$ P.R. $<2.5$ \\
\hline Total Backscatter Intensity & $500<$ B.S. $<1700$ & $<400$ & $<600$ \\
\hline Maximum Intensity ( \%) & $>0.5$ & $>0.3$ & $<0.2$ \\
\hline \multicolumn{4}{|c|}{ Total Backscatter/Forward Ratio vs. Polarized Backscatter/Forward Ratio } \\
\hline & Group A & Group B & Group C \\
\hline Shape & Cluster & Linear Increase & V shaped \\
\hline Polarized Backward/Forward Ratio & $<0.2$ & $>0.4$ & $<0.4$ \\
\hline Total Backscatter Intensity/Forward Ratio & $<0.4$ & $>0.3$ & $<0.3$ \\
\hline Maximum Intensity (\%) & $>0.6$ & $<1.0$ & $>1.0$ \\
\hline
\end{tabular}

feasibility of using the signature method in field sampling, additional signature plots were generated based on representative atmospheric loadings present during dust storms (see Supplement). While actual field testing is required, the results indicate that this CASPOL method may potentially be used during a dust storm or other intense atmospheric dust phenomena. In addition, the constraints summarized in Table 2 could be used to develop an algorithm which classifies remote sensing observations of various types of dust.

\subsection{Optical signatures of externally mixed ensemble aerosol}

As mentioned previously, Arizona test dust did not fit any of the signature groups. We speculate that this may be due to the fact that Arizona test dust is a multicomponent dust which is highly inhomogeneous. The Arizona test dust used in this study was primarily composed of three components, montmorillonite, kaolinite and hematite in weight percentages of $\sim 45,45$, and $10 \%$, respectively. Additional dust components appear in much smaller quantities as reported by the manufacturer (Powder Technology Inc., 2012), and are not included in this estimation. Figure 11 shows the measured signatures for Arizona test dust in panels a (total backscatter intensity vs. polarization ratio) and c (total backscatter to forward scatter ratio vs. polarized backscatter to forward scatter ratio). A composite signature for Arizona test dust can be generated using representative concentrations of the components of which it is comprised. Taking the additive combination of optical scattering signatures for montmorillonite, kaolinite and hematite (as discussed in Sect. 3.3) combined according to their known weight percentages produces the scattering signatures shown in Fig. $11 \mathrm{~b}$ and d. Comparison of the measured signature (panel a) to the composite (panel b) for the ratio of total backscatter intensity to polarization ratio shows good agreement for the shape and intensity of the signature. However, there is some difference in shape, in that
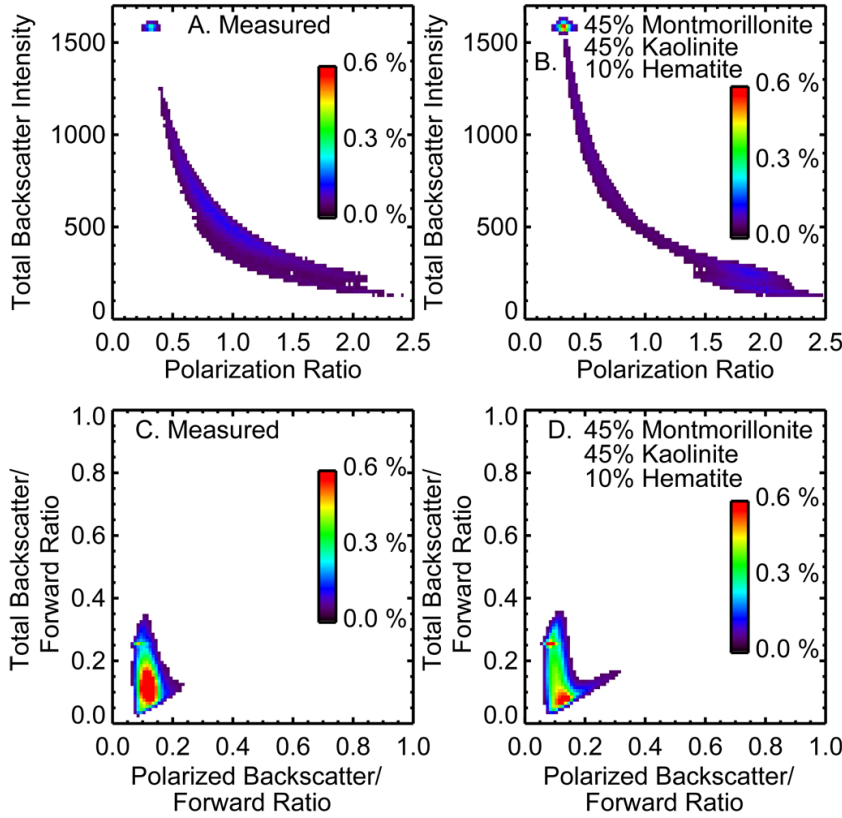

Fig. 11. The optical signature of measured Arizona test dust sample and the composite signature generated using montmorillonite, kaolinte and hematite data are shown in (a) and (b), respectively.

the composite signature has a narrower distribution in total backscatter intensity at a polarization ratio of $\sim 1.0$.

The composite total backscatter to forward scatter ratio vs. the polarized backscatter to forward scatter ratio signatures (Fig. 11d) is also very similar to the measured signature (Fig. 11c). The minor differences between the two panels are that the composite signature has a reduced intensity at a polarized backscatter to forward scatter ratios of $\sim 0.1$ and a slight protrusion of polarized backscatter to forward scatter ratios to values as high as $\sim 0.3$. While we have only generated composite vs. measured signatures for Arizona test 
dust thus far, this result for a single multi-component dust is very encouraging for the CASPOL instrument. This example suggests that it may be possible to predict the optical properties of real world dusts if only the major components of the dust are known. Future work will include CASPOL measurements and evaluation of additional external mixtures and their components.

\subsection{Estimated backward scattering cross sections}

The ability of the CASPOL to simultaneously measure the forward and backward scattering of light from a single particle allows for the calculation of the backward scattering cross section of particles based on the size resolved measurements. Assuming the olive oil droplets used in the calibration were spheres, the theoretical backscattering flux for light scattered over the angles in the backward direction collected by the CASPOL $\left(168-176^{\circ}\right)$ is attained using Mie theory and Eq. (3) below (Baron and Willeke, 2001).

$$
\text { Backscattering Flux }=\frac{4 \pi I}{k^{2}} \times \int_{168^{\circ}}^{176^{\circ}} \text { Backscatter }_{\text {Mie }}
$$

where $I$ is the laser intensity, $k$ is the size parameter, ( $k=\frac{2 \pi}{\lambda}$ ), and $\lambda$ is the wavelength of the CASPOL laser. Backscatter $_{\text {Mie }}$ is the calculated Mie response in the backward direction and is integrated over the collection angles of the CASPOL $\left(168^{\circ}\right.$ to $\left.176^{\circ}\right)$. Theoretical backscattering fluxes are calculated for all particle sizes used in the olive oil calibration. A spline fitting function is then applied to the total backscattering intensity (measured) vs. the backscatter flux data (calculated) to generate a function for converting measured backscattering intensity to backscattering flux. Next, scattering cross sections $\sigma$, are determined by Eq. (4).

$\sigma=\frac{\text { Backscattering Flux }}{I}$

where $I$ is the intensity of the incident CASPOL laser beam and the backscattering flux is taken from Eq. (3).

Using this method, an approximate backscattering cross section was determined for a $2.5 \mu \mathrm{m}$ spherical olive oil particle, $1.0 \times 10^{-9} \mathrm{~cm}^{-2}$. The following backscattering cross sections were calculated for $2.5 \mu \mathrm{m}$ particles representative of the three compositions; $4.1 \times 10^{-9} \mathrm{~cm}^{-2}$ for hematite, $5.3 \times 10^{-10} \mathrm{~cm}^{-2}$ for white quartz, and $7.3 \times 10^{-9} \mathrm{~cm}^{-2}$ for zeolite. The CASPOL data collected here illustrates the high degree of variability in the optical properties of atmospheric dusts depending on source composition, as demonstrated by the aerosol backscattering cross sections which vary by a factor of 7 or more. Another implication of these results is that detection of particles using backward scattering techniques such as lidar are subject to a high degree of uncertainty.

\section{Summary}

A new instrument, the CASPOL, was tested in a series of laboratory experiments using representative atmospheric dust samples available through commercial sources, and samples collected in various locations in Saudi Arabia and the Southwestern United States. The CASPOL data show a large variation in total backscatter intensity and polarization ratio as a function of dust type and particle size. Predicting the optical properties of aerosols is a challenge because of the multiple factors on which such properties depend, including a particle's composition, refractive index, aspect ratio, shape, and surface roughness. As these properties vary together rather than independently, it is generally not possible to extract cause and effect relationships between a single particle property and the resulting scattering properties. Since the CASPOL provides optical information on a single particle basis, the effects of size can be considered relative to other properties. However, because multiple particle properties varied even within a single size, defining their individual influence on optical properties was not possible.

For ensembles of particles, it was found that the plots of polarization ratio vs. total backscattering intensity could be used to differentiate between various types of dust. Differences in the optical scattering signatures observed in these plots were used to sort twelve of the thirteen surveyed dust types into three distinct groups. Only one dust, Arizona Test Dust, did not fit into any of these categories. Optical scattering signatures from the CASPOL data were used to develop a set of rules which can be used for classification of additional dusts sampled in the laboratory and during field campaigns. An analogous approach has been used to analyze backscatter signals and depolarization ratios observed by Cloud-Aerosol Lidar and Infrared Pathfinder Satellite Observations (CALIPSO) to infer cloud types (Cho et al., 2008). While not addressed in this manuscript, it is likely feasible to use CASPOL polarization ratio to backscattering intensity plots to differentiate between in-situ liquid droplets and nonspherical ice crystals. Thus, the CASPOL's potential as a field instrument may include characterization of cloud particles as well as dust.

We also demonstrated that using CASPOL data collected on individual components and the known ratio of those components, the overall optical signature for Arizona test dust can be predicted. While additional measurements of this type on other mixtures of dusts are needed, this implies that the Arizona test dust sample was externally mixed and that the optical properties of other atmospheric external mixtures may also be predicted through laboratory CASPOL measurements of their components.

Calculated backscattering cross sections show a factor of 7 difference between representative dust samples. This study demonstrates that dusts with different source regions and compositions have large variations in optical properties and ultimately in the scattering cross sections. As illustrated by 
the two Saudi Arabian samples, even a small change in geographical location may result in atmospheric dust with different optical properties.

In summary, the CASPOL provides valuable particle-byparticle measurements of size, total backscatter intensity and polarized backscatter intensity. Even within a narrow size range, scattering was observed to vary distinctly depending on the dust type. Differences are most likely due to a complex relationship between the size, shape, morphology, composition and refractive index. Although it was not possible to identify the dominant trait causing the differences in the optical properties observed here, a major finding of this work, that various dust types have distinctly different optical properties, has ramifications for other applications in atmospheric science. For example, our results imply that due to differences in aerosol shape and composition, lidar backscattering could vary greatly, even for dust particles of the same particle size (Brooks et al., 2004). Clearly, mineral dust type should be taken into account in interpretation of lidar data. Also, in future radiative transfer studies, the CASPOL data may be used to improve particle phase functions in which assumed particle size and shape are modified to produce backscattering cross sections consistent with the CASPOL observations. Such information will ultimately result in better remote sensing measurements, more accurate radiative transfer calculations, and a better understanding of aerosol direct effects on climate.

\section{Supplementary material related to this article is available online at: http://www.atmos-chem-phys.net/13/ 1345/2013/acp-13-1345-2013-supplement.pdf.}

Acknowledgements. The authors would like to thank Darrel Baumgardner for technical support of the CASPOL. Lei Bi, Chao Liu, and Ping Yang are thanked for insightful discussions and Mie scattering calculations, and Tom Gill is thanked for providing the White Sands, NM field sample. This research was supported by the National Science Foundation (CAREER-0548075) and the Norman Hackermann Advanced Research Program (Award \#160114).

Edited by: S. Schmidt

\section{References}

Arakawa, E. T., Tuminello, P. S., Khare, B. N., Millham, M. E., Authier, S., and Pierce, J.: Measurement of optical properties of small particles, 30 pp., Scientific Conference on Obscuration and Aerosol Research at Oak Ridge National Laboratory, ORNL/CP95872, 1997.

Attwood, A. R. and Greenslade, M. E.: Optical properties and associated hygroscopicity of clay aerosols, Aerosol Sci. Technol., 45, 1350-1359, doi:10.1080/02786826.2011.594462, 2011.

Baron, P. A. and Willeke, K.: Aerosol Measurement - Principles, Techniques, and Applications (2nd Edn.), John Wiley \& Sons, 2001.
Baumgardner, D., Jonsson, H., Dawson, W., O'Connor, D., and Newton, R.: The cloud, aerosol and precipitation spectrometer: a new instrument for cloud investigations, Atmos. Res., 59-60, 251-264, doi:10.1016/s0169-8095(01)00119-3, 2001.

Baumgardner, D., Brenguier, J. L., Bucholtz, A., Coe, H., DeMott, P., Garrett, T. J., Gayet, J. F., Hermann, M., Heymsfield, A., Korolev, A., Krämer, M., Petzold, A., Strapp, W., Pilewskie, P., Taylor, J., Twohy, C., Wendisch, M., Bachalo, W., and Chuang, P.: Airborne instruments to measure atmospheric aerosol particles, clouds and radiation: A cook's tour of mature and emerging technology, Atmos. Res., 102, 10-29, doi:10.1016/j.atmosres.2011.06.021, 2011.

Bi, L., Yang, P., Kattawar, G. W., and Kahn, R.: Single-scattering properties of triaxial ellipsoidal particles for a size parameter range from the Rayleigh to geometric-optics regimes, Appl. Optics, 48, 114-126, 2009.

Bohren, C. F. and Huffman, D. R.: Absorption and Scattering of Light by Small Particles, Wiley-VCH Verlag GmgH, Weinheim, Germany, 2004.

Brooks, S. D., Toon, O. B., Tolbert, M. A., Baumgardner, D., Gandrud, B. W., Browell, E. V., Flentje, H., and Wilson, J. C.: Polar stratospheric clouds during SOLVE/THESEO: Comparison of lidar observations with in situ measurements, J. Geophys. Res. 109, D02212, doi:10.1029/2003jd003463, 2004.

Bullard, J. E. and White, K.: Quantifying iron oxide coatings on dune sands using spectrometric measurements: An example from the Simpson-Strzelecki Desert, Australia, J. Geophys. Res., 107, 2125, doi:10.1029/2001jb000454, 2002.

Caquineau, S., Gaudichet, A., Gomes, L., and Legrand, M.: Mineralogy of Saharan dust transported over northwestern tropical Atlantic Ocean in relation to source regions, J. Geophys. Res., 107, 4251, doi:10.1029/2000jd000247, 2002.

Chen, Y., Kreidenweis, S. M., McInnes, L. M., Rogers, D. C., and DeMott, P. J.: Single particle analyses of ice nucleating aerosols in the upper troposphere and lower stratosphere, Geophys. Res. Lett., 25, 1391-1394, doi:10.1029/97g103261, 1998.

Cho, H.-M., Yang, P., Kattawar, G. W., Nasiri, S. L., Hu, Y., Minnis, P., Trepte, C., and Winker, D.: Depolarization ratio and attenuated backscatter for nine cloud types: analyses based on collocated CALIPSO lidar and MODIS measurements, Opt. Express, 16, 3931-3948, 2008

Curtis, D. B., Meland, B., Aycibin, M., Arnold, N. P., Grassian, V. H., Young, M. A., and Kleiber, P. D.: A laboratory investigation of light scattering from representative components of mineral dust aerosol at a wavelength of $550 \mathrm{~nm}$, J. Geophys. Res., 113, D08210, doi:10.1029/2007jd009387, 2008.

DMT Manual: The Cloud Aerosol Spectrometer - Depolarization Option Operator Manual, DOC-0167 Revision C, DMT, Boulder, Colorado, USA, 2011.

Duce, R. A. and Tindale, N. W.: Atmospheric transport of iron and its deposition in the ocean, Limnol. Oceanogr, 36, 1715-1726, 1991.

Ellis, E. A. and Pendleton, M. W.: Vapor coating: A simple, economical procedure for preparing difficult specimens for Scanning Electron Microscopy, Microscopy Today, 15, p. 44, 2007.

Filmetrics: Refractive Index Database, http://www.filmetrics.com/ refractive-index-database (last access: 22 August 2012), 2011.

Goudie, A. S. and Middleton, N. J.: Saharan dust storms: nature and consequences, Earth-Sci. Rev., 56, 179-204, doi:10.1016/s0012- 
8252(01)00067-8, 2001.

Harris-Hobbs, R. L. and Cooper, W. A.: Field evidence supporting quantitative predictions of secondary ice production rates, J. Atmos. Sci., 44, 1071-1082, doi:10.1175/15200469(1987)044<1071:fesqpo > 2.0.co;2, 1987.

IPCC: Climate Change 2007: The Physical Science Basis. Contribution of Working Group I to the Fourth Assessment Report of the Intergovernmental Panel on Climate Change, Cambridge, United Kingdom and New York, NY, USA, 996 pp., 2007.

Ivlev, L. S. and Popova, S. I.: The complex refractive index of substances in the atmospheric aerosol dispersed phase, Izv. Russ. Acad. Sci. Atmos. Ocean. Phys., 95, 87-91, 1973.

Kanji, Z. A. and Abbatt, J. P. D.: Ice nucleation onto Arizona test dust at cirrus temperatures: Effect of temperature and aerosol size on onset relative humidity, J. Phys. Chem. A, 114, 935-941, doi:10.1021/jp908661m, 2009.

Kerker, M., Scheiner, P., Cooke, D. D., and Kratohvil, J. P.: Absorption index and color of colloidal hematite, J. Colloid Interf. Sci., 71, 176-187, doi:10.1016/0021-9797(79)90231-5, 1979.

Li, I. L., Fu, L., Li, H., Zhai, J., and Ruan, S.: Refraction indices measurement of hexagonal zeolite crystal using Brewster angle method, Adv. Mat. Res., 3, 146-147, doi:10.4028/www.scientific.net/AMR.146-147.429, 2010.

Liu, B. Y. H., Berglund, R. N., and Agarwal, J. K.: Experimental studies of optical particle counters, Atmos. Environ., 8, 717-732, doi:10.1016/0004-6981(74)90163-2, 1974.

Mishchenko, M. I., Travis, L. D., Kahn, R. A., and West, R. A.: Modeling phase functions for dustlike tropospheric aerosols using a shape mixture of randomly oriented polydisperse spheroids, J. Geophys. Res., 102, 16831-16847, doi:10.1029/96jd02110, 1997.

Morgan, W. T., Allan, J. D., Bower, K. N., Esselborn, M., Harris, B., Henzing, J. S., Highwood, E. J., Kiendler-Scharr, A., McMeeking, G. R., Mensah, A. A., Northway, M. J., Osborne, S., Williams, P. I., Krejci, R., and Coe, H.: Enhancement of the aerosol direct radiative effect by semi-volatile aerosol components: airborne measurements in North-Western Europe, Atmos. Chem. Phys., 10, 8151-8171, doi:10.5194/acp-10-81512010, 2010.

Peters, T. M., Riss, A. L., Holm, R. L., Singh, M., and Vanderpool, R. W.: Design and evaluation of an inlet conditioner to dry particles for real-time particle sizers, J. Environ. Monit., 10, 541-551, 2008.

Powder Technologies Inc.: Arizona Test Dust Composition, 2012.

Polyanskiy, M.: refractiveindex.info Database, http: //refractiveindex.info, last access: 22 August 2012.
Prospero, J. M.: Saharan dust impacts and climate change, Oceanography, 19, 60-61, 2006.

Prospero, J. M., Bonatti, E., Schubert, C., and Carlson, T. N.: Dust in the Caribbean atmosphere traced to an African dust storm, Earth Planet. Sc. Lett., 9, 287-293, doi:10.1016/0012821x(70)90039-7, 1970.

Prospero, J. M., Olmez, I., and Ames, M.: Al and Fe in $\mathrm{PM}_{2.5}$ and $\mathrm{PM}_{10}$ suspended particles in South Central Florida: The impact of the long range transport of African mineral dust, J. Water Air Soil Pollut., 125, 291-317, 2001.

Sassen, K.: The polarization lidar technique for cloud research: A review and current assessment, B. Am. Meteorol. Soc., 72, 18481866, doi:10.1175/1520-0477(1991)072<1848:tpltfc > 2.0.co;2, 1991.

Sassen, K.: Indirect climate forcing over the western US from Asian dust storms, Geophys. Res. Lett., 29, 1465, doi:10.1029/2001g1014051, 2002.

Schlegel, A., Alvarado, S. F., and Wachter, P.: Optical properties of magnetite $\left(\mathrm{Fe}_{3} \mathrm{O}_{4}\right)$, J. Phys. C Solid State, 12, 1157 doi:10.1088/0022-3719/12/6/027, 1979.

Sugimoto, N., Matsui, I., Shimizu, A., Uno, I., Asai, K., Endoh, T., and Nakajima, T.: Observation of dust and anthropogenic aerosol plumes in the Northwest Pacific with a two-wavelength polarization lidar on board the research vessel Mirai, Geophys. Res. Lett., 29, 1901, doi:10.1029/2002gl015112, 2002.

TSI Manual: Model 3450 Vibrating Orifice Aerosol Generator Manual, TSI, Place of publication: Shoreview, Minnesota 2002.

Uematsu, M., Wang, Z., and Uno, I.: Atmospheric input of mineral dust to the western North Pacific region based on direct measurements and a regional chemical transport model, Geophys. Res. Lett., 30, 1342, doi:10.1029/2002g1016645, 2003.

West, R. A., Doose, L. R., Eibl, A. M., Tomasko, M. G., and Mishchenko, M. I.: Laboratory measurements of mineral dust scattering phase function and linear polarization, J. Geophys. Res., 102, 16871-16881, doi:10.1029/96jd02584, 1997.

Xu, J., Bergin, M. H., Greenwald, R., Schauer, J. J., Shafer, M. M., Jaffrezo, J. L., and Aymoz, G.: Aerosol chemical, physical, and radiative characteristics near a desert source region of northwest China during ACE-Asia, J. Geophys. Res., 109, D19S03, doi:10.1029/2003jd004239, 2004.

Yunus, W. M. M., Fen, Y. W., and Yee, L. M.: Refractive Index and Fourier Transform Infrared Spectra of Virgin Coconut Oil and Virgin Olive Oil, Am. J. Appl. Sci., 6, 328-331, doi:10.3844/ajassp.2009.328.331, 2009. 